\title{
Underexpression of $\alpha$-1-microglobulin/bikunin precursor predicts a poor prognosis in oral squamous cell carcinoma
}

\author{
SHOICHI SEKIKAWA ${ }^{1}$, TAKESHI ONDA ${ }^{1}$, NAMI MIURA ${ }^{2}$, TAKESHI NOMURA $^{3}$, \\ NOBUO TAKANO $^{4}$, TAKAHIKO SHIBAHARA ${ }^{1}$ and KAZUFUMI HONDA ${ }^{2}$ \\ ${ }^{1}$ Department of Oral and Maxillofacial Surgery, Tokyo Dental College, Chiba 261-8502; \\ ${ }^{2}$ Department of Biomarkers for Early Detection of Cancer, National Cancer Center Research Institute, Tokyo 104-0045; \\ ${ }^{3}$ Department of Oral Medicine, Oral and Maxillofacial Surgery, and ${ }^{4}$ Oral Cancer Center, \\ Tokyo Dental College, Chiba 272-8513, Japan
}

Received April 16, 2018; Accepted August 24, 2018

DOI: 10.3892/ijo.2018.4581

\begin{abstract}
In the present study, in order to identify novel diagnostic biomarkers for the malignant behavior of oral squamous cell carcinoma (OSCC), we determined the proteomic profiles of several OSCC cell lines and keratinocytes by two-dimensional fluorescence difference gel electrophoresis and liquid chromatography tandem mass spectrometry. The protein expression level of $\alpha$-1-microglobulin/bikunin precursor (AMBP) was found to be significantly lower in the OSCC cell lines than in the keratinocytes, and a significant decrease in AMBP mRNA expression was confirmed in the OSCC cell lines by RT-qPCR. To investigate the biological function of AMBP in OSCC, the cells were transiently transfected with an AMBP overexpression vector; the AMBPoverexpressing cells exhibited a significantly decreased invasion and migration in comparison to the mock-transfected control cells, although no significant changes in cell proliferation were observed. Immunohistochemistry revealed that the underexpression of AMBP was significantly associated with a high metastatic potential to cervical lymph nodes and a poor overall survival. Thus, the expression of AMBP is an independent predictive factor of cervical lymph node metastasis and a prognostic factor of overall survival, and it is involved in both cell invasion and metastasis in cervical lymph nodes in OSCC.
\end{abstract}

\section{Introduction}

Head and neck cancer accounts for approximately 550,000 new cases and approximately 300,000 deaths each year worldwide (1). Oral squamous cell carcinoma (OSCC) is the

Correspondence to: Dr Takeshi Onda, Department of Oral and Maxillofacial Surgery, Tokyo Dental College, 1-2-2 Masago, Mihama-ku, Chiba 261-8502, Japan

E-mail: ondatake@tdc.ac.jp

Key words: oral cancer, squamous cell carcinoma, prognostic biomarker, $\alpha$-1-microglobulin/bikunin precursor, two-dimensional fluorescence difference gel electrophoresis most common malignancy of the head and neck (2) and is among the 10 most common types of cancer worldwide (3). The OSCC incidence rates have significantly increased in several countries, such as Iceland, Finland and Ireland between the years 2000-2007 (4), and it has been reported that the incidence among young individuals and women has increased (5-7). Both the overall and 5-year survival rates for OSCC are approximately 60\%, although there are variations from 10 to $82 \%$, depending on clinical stage, age, race, comorbidity and the primary site of the tumor (8). Among several prognostic factors, it has been shown that nodal metastasis is the strongest factor that predicts a poor survival $(8,9)$. Therefore, the diagnosis and management of nodal metastases are important for improving the survival rate (8). Surgical resection is the first choice of treatment for patients with oral cancer. Although definitive radiation therapy is effective, it is not routinely used as osteoradionecrosis occurs frequently; thus, chemoradiotherapy is used as an adjuvant post-operative treatment (8). However, surgical resection for locally advanced cases decreases the quality of life (QOL) of patients due to post-operative dysfunctions, such as dysphagia and pronunciation/anarthria by amputation of the facial nerve and/or deglutition-related muscles, and through cosmetic disturbances, such as major changes in the form of the face by tissue defects (10). It is thus necessary to consider not only the excision of the cancer, but also the preservation of facial function. More precise diagnostic biomarkers and prognostic factors to inform multidisciplinary treatment strategies, including radiotherapy, chemotherapy, and molecular targeted therapy, are necessary. A number of researchers are searching for tumor biomarkers that indicate the properties of tumor cells or that can be used as treatment targets $(11,12)$. Two-dimensional fluorescence difference gel electrophoresis (2D-DIGE) is a widely used tool for separating proteins (13), and proteomic approaches have been used to identify useful biomarkers for various types of cancer, such as prostate, breast and colon $(14,15)$. However, there are few studies using proteomic approaches by 2D-DIGE for oral cancers $(16,17)$.

In the present study, we analyzed the expression of proteins in normal epidermis keratinocytes and OSCC cell lines using 2D-DIGE and liquid chromatography tandem mass 
spectrometry (LC/MS/MS). We then performed a functional analysis of $\alpha$-1-microglobulin/bikunin precursor (AMBP), which we identified by in vitro assays. Recently, the associations between AMBP and various malignant tumors have been reported $(18,19)$. Although the functions of AMBP in malignant tumors remain unclear, there are reports indicating that the antitumor effects of bikunin, a degradation product of AMBP, is associated with the urokinase-type plasminogen activator (uPA) and urokinase-type plasminogen activator receptor (UPAR) pathway or the mitogen-activated protein kinase (MAPK) signaling pathway $(20,21)$. In this study, we evaluated the association between AMBP expression and clinicopathological factors and prognosis by immunohistochemistry (IHC) to identify its clinical significance.

\section{Materials and methods}

Cell lines and materials. The OSCC cell lines, KON, OSC-20, HSC-3, HSC-4, SAS and Ca9-22, were obtained from the Japanese Collection of Research Bioresources Cell Bank, Osaka, Japan. A spontaneously transformed immortal keratinocyte cell line, HaCaT (\#300493), was obtained from CLS Cell Lines Service GmbH (Eppelheim, Germany). All cell lines were maintained at $37^{\circ} \mathrm{C}$ in a humidified atmosphere of $5 \% \mathrm{CO}_{2} / 95 \%$ air. Fetal bovine serum (FBS) was purchased from Sigma-Aldrich (St. Louis, MO, USA). The KON cells were cultured in Dulbecco's modified Eagle's medium (DMEM) (Sigma-Aldrich) supplemented with 10\% FBS. The OSC-20 cells were cultured in DMEM/F-12 medium (Sigma-Aldrich). The HSC-3, HSC-4 and Ca9-22 cells were cultured in minimum essential medium (MEM) (Sigma-Aldrich) supplemented with $10 \%$ FBS. SAS was cultured in DMEM/F-12 with 10\% FBS. Culture medium exchange was carried out twice a week for all cells. HaCaT, used as the control cells, were cultured in DMEM supplemented with $10 \%$ FBS. AMBP-overexpressing SAS and mock-transfected cells were cultured in DMEM/F-12 with $10 \%$ FBS.

2D-DIGE and image analysis. 2D-DIGE was performed as previously described $(22,23)$. In brief, a common internal control sample was created by mixing a small portion of all protein samples used in this study, which was labeled with Cy3 fluorescent dye (CyDye DIGE Fluor Saturation Labelling Dyes; GE Healthcare Biosciences, Uppsala, Sweden). Individual samples were labeled with Cy5 fluorescent dye (CyDye DIGE Fluor Saturation Labelling Dyes; GE Healthcare Biosciences). Each differently labeled $50 \mu \mathrm{g}$ protein sample was mixed together and separated by 2D-DIGE according to the isoelectric point and molecular weight. The first-dimension separation was achieved using a $24 \mathrm{~cm}$ length immobilized $\mathrm{pH}$ gradient gel (pH 3-10) and a Multiphor Electrophoresis System (both from GE Healthcare Biosciences), while the second-dimension separation was achieved using a $12 \%$ acrylamide gel with a separation distance of $36 \mathrm{~cm}$. The gels were scanned using the laser scanner Typhoon Trio (GE Healthcare Biosciences) at the appropriate wavelength for $\mathrm{Cy} 3$ or $\mathrm{Cy} 5$. For all protein spots, the Cy5 intensity was normalized with the Cy3 intensity in the same gel using Progenesis SameSpots software version 3 (Nonlinear Dynamics, Newcastle, UK) so that gel-to-gel variations were canceled out.
Mass spectrometry analysis. Proteins separated by $12 \%$ SDS-polyacrylamide gel electrophoresis (PAGE) were visualized by SYPRO Ruby staining (Molecular Probes, Eugene, OR, USA). Peptide samples were excised from the gels and digested by trypsin using an In Gel Digest kit (Millipore, Bedford, MA, USA) as previously described (24). Following peptide extraction, the proteolytic peptide mixture was concentrated to $5 \mathrm{ml}$ by evaporation, $35 \mathrm{ml}$ of $2 \%$ acetonitrile and $0.1 \%$ trifluoroacetic acid (TFA) was added, and then it was subjected to an HTC-PAL autosampler (CTC Analytics AG, Zwingen, Switzerland) for nanoscale capillary LC/MS/MS analysis. We used the capillary LC system Magic 2002 (Michrom BioResources, Brockville, ON, Canada) coupled to an in-line nanoelectrospray mass spectrometer LCQ Advantage (Thermo Finnigan, Yokohama, Japan) with a silica-coated glass capillary PicoTip installed (New Objective, Woburn, MA, USA). The samples were loaded in 5\% acetonitrile with $0.1 \%$ formic acid. The gradient consisted of $6.4 \%$ acetonitrile for $5 \mathrm{~min}$ and subsequently 6.4-76.8\% acetonitrile for $45 \mathrm{~min}$. Spectra were collected as MS and MS/MS scans. The MS scan defined the ion composition at an $\mathrm{m} / \mathrm{z}$ range of 450-2000, and the MS/MS scan acquired the mass spectrum of the parental ion upon collision-induced dissociation. The acquired collision-induced dissociation spectra were analyzed by direct inspection using the Mascot software program version 2.2.04 (Matrix Science, Boston, MA, USA), as previously described $(25,26)$.

Analysis of $m R N A$ expression by reverse transcription-quantitative PCR. The mRNA expression levels of AMBP were examined in 6 OSCC-derived cell lines and in $\mathrm{HaCaT}$ cells. Total RNA was isolated from the cells using TRIzol reagent (Invitrogen, Carlsbad, CA, USA) and was reverse transcribed by Ready-to-GO You-prime first-strand beads (GE Healthcare UK Ltd., Little Chalfont, UK) and Oligo(dT) primer (Invitrogen) (27,28). Quantitative (real-time) reverse transcription polymerase chain reaction ( $\mathrm{PPCR}$ ) was performed to evaluate the expression levels of AMBP mRNA. All-qPCR analyses were performed using a LightCycler 480 PCR system (Roche Diagnostics GmbH, Mannheim, Germany). The reaction mixture was loaded and submitted to an initial denaturation at $95^{\circ} \mathrm{C}$ for $10 \mathrm{~min}$, followed by 45 rounds of amplification at $95^{\circ} \mathrm{C}(10 \mathrm{sec})$ for denaturation, $62^{\circ} \mathrm{C}(10 \mathrm{sec})$ for annealing, and $72^{\circ} \mathrm{C}$ for extension, with a temperature slope of $20^{\circ} \mathrm{C} / \mathrm{sec}$. The primer sequences for AMBP were forward, 5'-TACATCCAT GGCCTGTGAGA-3'; and reverse, 3'-CCACTACCACTACT CCTGGA-5'. The transcript level for the AMBP gene was estimated from the respective standard curves and normalized to the amount of glyceraldehyde-3-phosphatedehydrogenase (GAPDH) 5'-CATCTCTGCCCCCTCTGCTGA-3' and 5'-GGATGACCTTGCCCACAGCCT-3' transcript determined in corresponding samples. qPCR was performed as previously described (29). The results obtained using the $2^{-\Delta \Delta C q}$ method (30).

Cloning AMBP into an expression vector. The full-length human AMBP cDNA clone was purchased from the Kazusa DNA Research Institute, Chiba, Japan. The AMBP cDNA clone that excluded signal peptide was amplified by PCR using PrimeSTAR max DNA polymerase (Takara Bio, Kyoto, Japan) and the primers 5'-AGCTGCTAGCAAGCTACCATGAGGAGCCTC 
GGG-3' and 3'-TCGACGATCGTTCGATGGTACTCCTCG GAGCCC-5'. The PCR product was extracted from the agarose gel and ligated into the HindIII-BamHI site of pCEP4 Mammalian expression vector (Life Technologies, Carlsbad, CA, USA) using an In-Fusion HD Cloning kit (Clontech, Mountain View, CA, USA). Subsequent transformation was performed in competent DH5 $\alpha$ cells (Takara Bio) via the heat shock method. The true transformed colonies were selected through colony-PCR and confirmed by DNA sequencing.

Transfection of AMBP into SAS cells. SAS cells plated at a density of $4 \times 10^{5}$ cells in 6 -well plates were transfected with $2.0 \mu \mathrm{g}$ of the AMBP-pCEP4 construct or pCEP4 vector alone (mock) using ViaFect Transfection Reagent (Promega Corp., Madison, WI, USA) in accordance with the manufacturer's instructions. All experiments using these cells were performed at $48 \mathrm{~h}$ following transfection.

Western blot analysis. Western blot analysis was performed to confirm the transfection efficiency. Total protein from AMBPoverexpressing SAS and mock-transfected SAS cells was isolated using M-PER Mammalian Protein Extraction Reagent containing protease and phosphatase inhibitor cocktail, and quantified using the Qubit Protein Assay kit (all from Thermo Fisher Scientific, Tokyo, Japan). Isolated proteins (20 $\mu \mathrm{g})$ were resolved on $4-12 \%$ polyacrylamide gels and transferred onto PVDF membranes. The membranes were incubated in Blocking One blocking buffer (Nacalai Tesque, Kyoto, Japan) for $30 \mathrm{~min}$ at room temperature. AMBP monoclonal antibody (4F4; Abnova, Taipei, Taiwan) was used at a dilution of 1:1,000, and secondary antibody Anti-Mouse IgG, HRP-Linked F(ab')2 Fragment Sheep (NA9310) (GE Healthcare UK Ltd.) was used at a dilution of 1:1,000. $\beta$-actin antibody was used as the internal control at a dilution of 1:2,500 (ab6276; Abcam plc, Cambridge, UK). Following overnight incubation at $4^{\circ} \mathrm{C}$ with primary antibodies, the membranes were further incubated with the secondary antibodies for $2 \mathrm{~h}$ at room temperature. Signals were detected with ECL Western Blotting Detection Reagents (GE Healthcare UK Ltd.), according to the manufacturer's instructions. Quantitative analysis of $\mathrm{AMBP} / \beta$-actin were performed using Fusion Capt software (Vilber Lourmat, Marne-la-Vallee, France).

Wound healing assay. AMBP-overexpressing SAS or mocktransfected SAS cells were seeded into culture inserts (80206; Ibidi GmbH, Munich, Germany) at $3.0 \times 10^{5}$ cells/insert in triplicate. Following incubation for $24 \mathrm{~h}$ until confluence, the inserts were removed, and a gap was made. After washing with PBS to remove cell debris, fresh culture medium was added, and cells were incubated at $37^{\circ} \mathrm{C}$ in a $5 \% \mathrm{CO}_{2}$ humidified incubator to allow for wound closure. The closure of the gap was photographed at x200 magnification under Nikon TE-DH100W microscope (Nikon Corporation, Tokyo, Japan) immediately after adding fresh culture medium and at the indicated time points ( 6 and $8 \mathrm{~h}$ later). The gap area of each time point was calculated using the MTrackJ plugin (http://www. imagescience.org/meijering/software/mtrackj/manual/) with ImageJ software (version 1.50) (NIH, Bethesda, MD, USA).

Matrigel cell invasion assay. Matrigel invasion was performed using Corning BioCoat Matrigel Invasion Chambers
(Corning, Inc., Corning, NY, USA). AMBP-overexpressing SAS or mock-transfected SAS cells $\left(1 \times 10^{5}\right.$ cells $)$ that were suspended in serum-free culture medium were seeded in the upper surface of each insert chamber. The lower part was filled with culture medium with $10 \%$ FBS. Following 48 h of incubation at $37^{\circ} \mathrm{C}$ in a $5 \% \mathrm{CO}_{2}$ humidified incubator, cells that had migrated into the other side of the membrane were stained with Diff-Quick stain (16920; SYSMEX, Hyogo, Japan). Briefly, the membranes were treated with Diff-Quick fixative for $5 \mathrm{~min}$, Diff-Quick Solution I for $5 \mathrm{~min}$, and Diff-Quick Solution II for $5 \mathrm{~min}$, washed in deionized water, allowed to air dry, mounted on slides. All steps were carried out at room temperature. The total number of migrated cells in all fields was counted using the Cell Counter plugin with ImageJ software (version 1.50) (NIH, Bethesda, MD, USA). The experiments were performed in triplicate.

Cell proliferation assay. AMBP-overexpressing SAS or mocktransfected SAS cells were plated at a density of $5 \times 10^{3}$ cells/well into 96 -well plates in sextuplicate, and the plates were then incubated at $37^{\circ} \mathrm{C}$ in a humidified $5 \% \mathrm{CO}_{2}$ atmosphere. Cell viability was measured with the RealTime-Glo MT Cell Viability assay every $12 \mathrm{~h}$ using a GloMax 96 Microplate Luminometer (both from Promega Corp.).

Patients and specimens. We evaluated AMBP expression and clinicopathological records in 95 OSCC specimens of the tongue, from 60 males and 35 females ranging in age from 30 to 88 years, with an average age of 67 years, who had undergone surgical excision in the Oral Cancer Center, Tokyo Dental College, Chiba, Japan from January, 2010 to March, 2016. Patient distributions based on the Union for International Cancer Control (UICC) TNM Classification of Malignant Tumors 7th Edition staging were as follows: 32 patients had stage I, 27 had stage II, 11 had stage III, and 25 had stage IV disease. Analysis of the histopathological grade diagnosed 80 patients with well-differentiated, 10 with moderatelydifferentiated and 5 with poorly-differentiated OSCC. The depth of invasion (DOI) was measured on histopathological specimens of the tumors as per the American Joint Committee on Cancer (AJCC) Cancer Staging Manual, 8th Edition (31). For primary surgery, 58 cases underwent glossectomy alone, and 37 cases underwent surgical excision and cervical neck dissection, including elective neck dissection. The duration of the follow-up time for all 95 cases was 12.8 months to 88.3 months, and the median follow-up time was 45.7 months. The duration of follow-up time for 58 clinically node-negative (cN0) cases who did not undergo elective neck dissection was 9.2 months to 80.0 months, and the median follow-up time was 53.9 months. Lymph node metastases were found in 43 cases. Distant metastases were found in 16 cases, and death occurred in 15 cases. This study was approved by the Research Ethics Committee of Tokyo Dental College (no. 709), and informed consent was obtained from the patients according to a protocol.

Immunohistochemistry (IHC). For IHC, the tissue sections were de-paraffined with xylene and rehydrated through an ethanol series and PBS. Antigen retrieval was performed by heat treatment by microwaving for $20 \mathrm{~min}$ with citrate buffer, 

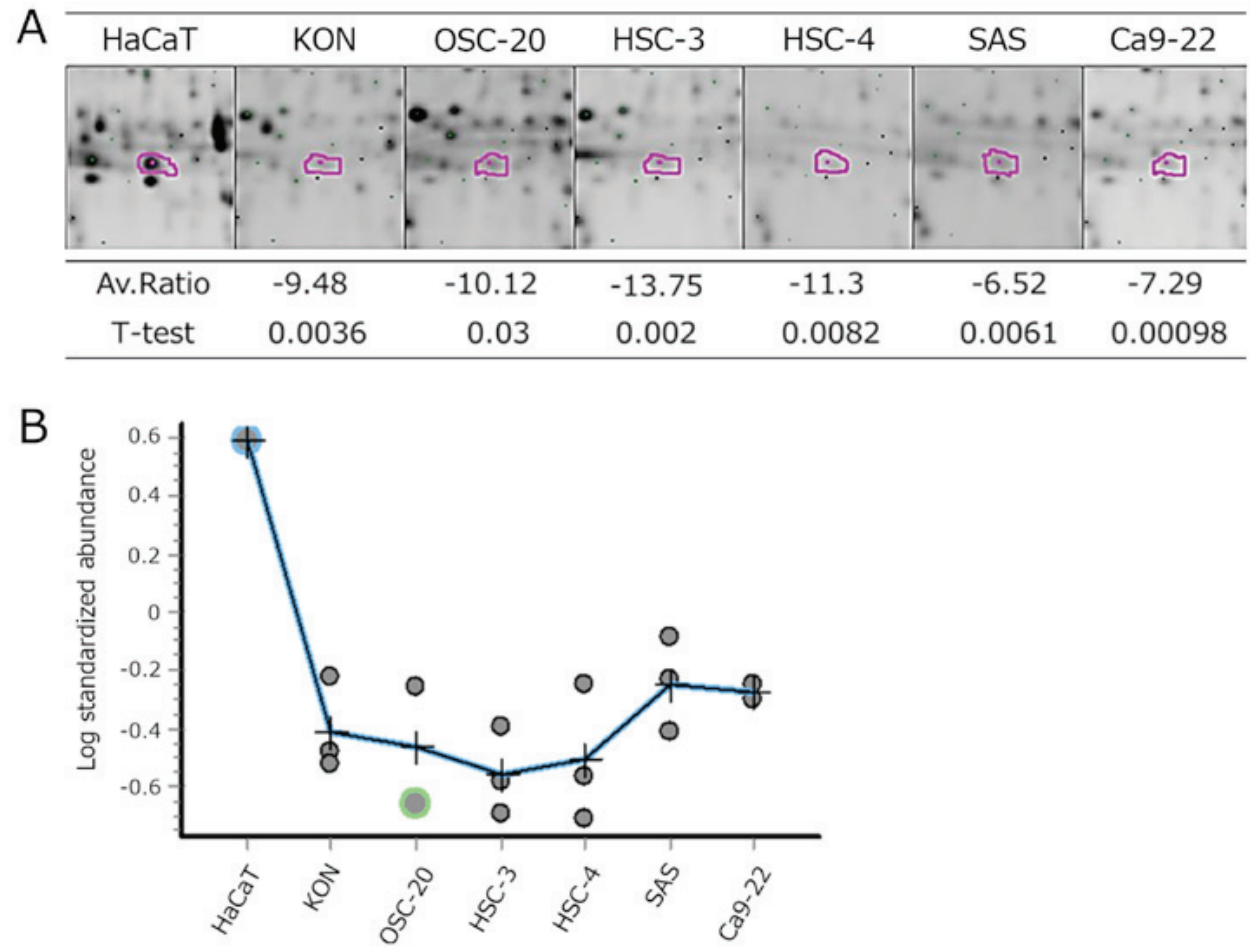

Figure 1. AMBP expression levels in HaCaT and OSCC cell lines. (A) The electrophoretic patterns of AMBP of each cell line are shown. (B) AMBP protein exhibited a decreased expression common among the OSCC cell lines as compared with the normal HaCaT keratinocytes. AMBP, $\alpha-1-\mathrm{microglobulin} / \mathrm{bikunin}$ precursor; OSCC, oral squamous cell carcinoma.

pH 6.0. Endogenous peroxidase was blocked with $0.3 \% \mathrm{H}_{2} \mathrm{O}_{2}$ in methanol for $30 \mathrm{~min}$, followed by incubation with Protein Block (Genostaff, Tokyo, Japan). The sections were incubated with anti-AMBP mouse monoclonal antibody $(2 \mu \mathrm{g} / \mathrm{ml} ; 4 \mathrm{~F} 4$, Abnova) at $4^{\circ} \mathrm{C}$ overnight, then incubated with Histofine Simple Stain MAX-PO MULTI (Nichirei, Tokyo, Japan) for $30 \mathrm{~min}$ at room temperature. Peroxidase activity was visualized by diaminobenzidine. The sections were counterstained with Mayer's hematoxylin (MUTO, Tokyo, Japan) for $3 \mathrm{sec}$ at room temperature, dehydrated, and then mounted with Malinol (MUTO). The stained sections were scanned using the NanoZoomer2.0-HT (Hamamatsu Photonics, Hamamatsu, Japan). Scanned images were constructed NanoZoomer Digital Pathology version 2.6 (Hamamatsu Photonics). Scanned sections were examined and scored using a semiquantitative immunoreactive score (IRS) as previously described (32). The mean dye intensity was assessed using the following scale: 0 , negative; 1 , weak; 2 , moderate; and 3 , strong. The percentages of stained cells from 5 randomly selected fields under high magnification $(\mathrm{x} 400)$ were counted. The percentage of stained cells varied as follows: 0 , negative; $1,<10 \% ; 2,10 \%$ to $50 \% ; 3,51 \%$ to $80 \% ; 4,>80 \%$ positive cells The product of both summands yields a total score ranging from 0 to 12 points. According to these scores, tissues were classified as low (0-4 points) or high (6-12 points) AMBP expression groups.

Statistical analysis. All in vitro assays were evaluated using t-tests and Kruskal-Wallis tests with Bonferroni's correction applied. Correlative significance of AMBP expression to clinicopathological factors was evaluated by Fisher's exact test. The overall survival rate and secondary cervical lymph node metastasis control rate were calculated by Kaplan-Meier analysis, and comparisons between each group were measured using log-rank tests. Cox hazard regression analysis was performed as univariate and multivariable analyses to detect risk factors for death. All statistical analyses were performed with EZR version 1.36 (Saitama Medical Center, Jichi Medical University, Saitama, Japan), which is a graphical user interface for R (The R Foundation for Statistical Computing, Vienna, Austria). More precisely, it is a modified version of $\mathrm{R}$ Commander designed to add statistical functions frequently used in biostatistics (33). All P-values were two sided, and $\mathrm{P}$-values $\leq 0.05$ were considered to indicate statistically significant differences.

\section{Results}

Proteomic profiling by 2D-DIGE. Protein samples were extracted from OSCC-derived cell lines and $\mathrm{HaCaT}$ cells. Approximately 3,000 protein spots were successfully detected from each proteome. There were 49 significantly increased proteins and 77 significantly decreased proteins in the OSCC cells compared with the HaCaT cells (data not shown).

Protein identification. In total, 92 proteins were identified, apart from those with post-translational modifications, by LC/MS/MS. AMBP was listed as a candidate protein as AMBP exhibited a decreased expression most prominently in each OSCC cell line we examined (Fig. 1).

$m R N A$ expression analysis. We examined mRNA expression by RT-qPCR in the OSCC and HaCaT cells. The mRNA expression of AMBP was significantly decreased in all the OSCC cells as compared with the HaCaT cells $(\mathrm{P}=0.012$; Fig. 2$)$. 


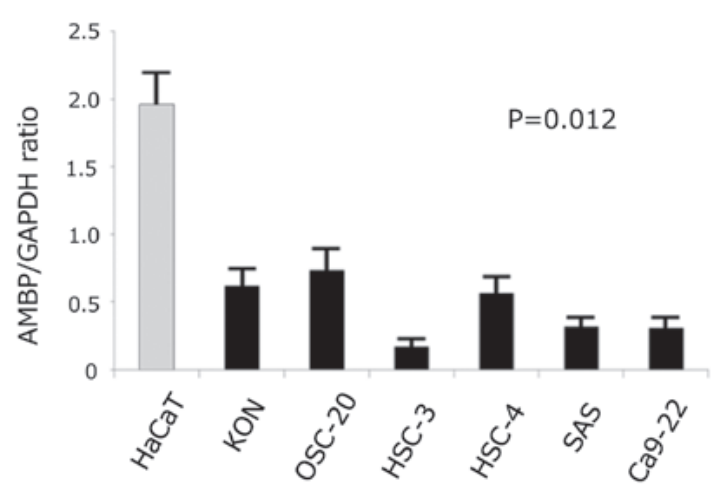

Figure 2. Quantification of the mRNA levels of AMBP in OSCC cell lines by RT-qPCR analysis. The significant downregulation of the AMBP gene was observed in all OSCC cell lines as compared with the normal HaCaT keratinocytes. AMBP, $\alpha$-1-microglobulin/bikunin precursor; OSCC, oral squamous cell carcinoma.

Evaluation of AMBP functions in vitro. Following the transient transfection of the SAS cells with the AMBP overexpression vector, western blot analysis revealed that AMBP protein was successfully expressed in these cells. It was not transfected in the other cell lines . Quantitative analysis of AMBP/ $\beta$-actin revealed that AMBP-overexpressing SAS cells had a ratio of 1.60, while for the mock-transfected SAS cells, this was $<0.01$. (Fig. 3A). The cell migratory and invasive ability of AMBP-overexpressing SAS cells was significantly decreased as compared with that of the mock-transfected SAS cells, as shown by wound healing assays $(\mathrm{P}<0.01$; Fig. 3B and $\mathrm{C})$ and Matrigel cell invasion assays $(\mathrm{P}=0.014$; Fig. 3D and $\mathrm{E})$. No statistically significant differences in cell proliferation were observed between AMBP-overexpressing SAS and mock-transfected SAS cells (Fig. 3F).

IHC. We examined AMBP expression in normal oral mucosa samples and 95 OSCC patient specimens of the tongue by IHC. AMBP expression was clearly detectable in the epithelium of the normal oral mucosa (Fig. 4A). In the OSCC specimens, AMBP expression tended to decrease as compared with that of the normal oral mucosa, and 38 cases had a low AMBP expression, while 57 cases had a high expression according to the IRS (Fig. 4B-D and Table I).

Association between AMBP expression and clinicopathological factors, and Kaplan-Meier analysis. The association between the clinicopathological factors and AMBP expression in the tongue OSCC specimens is shown in Table I. Statistically significant associations between the clinicopathological factors and AMBP expression were observed in DOI $(\mathrm{P}=0.0202)$, lymph node metastasis $(\mathrm{P}=0.0015)$ and mortality $(\mathrm{P}=0.0415)$ by Fisher's exact test. Kaplan-Meier analysis revealed that the underexpression of AMBP was significantly associated with poor outcomes in the overall survival rate of the 95 patients $(\mathrm{P}=0.0165)$ and in secondary cervical lymph node metastasis of the $58 \mathrm{cN} 0$ patients who did not undergo elective neck dissection ( $\mathrm{P}=0.0104)$ by the log-rank test (Fig. 5).

Hazard ratios for death in patients with OSCC of the tongue. We calculated the hazard ratios (HR) of certain factors, including age, sex, $\mathrm{T}$ classification, $\mathrm{N}$ classification, clinical stage, histological grade and AMBP protein expression for
Table I. Association of AMBP and clinicopathological characteristics of patients with OSCC.

\begin{tabular}{|c|c|c|c|c|}
\hline \multirow[b]{2}{*}{ Variable } & \multirow{2}{*}{$\frac{\text { No. of patients }}{n=95 ; n(\%)}$} & \multicolumn{3}{|c|}{ AMBP expression } \\
\hline & & Low & High & P-value \\
\hline \multicolumn{5}{|l|}{ Age, years } \\
\hline$<67$ & $51(53.7)$ & 18 & 33 & 0.401 \\
\hline$\geq 67$ & $44(46.3)$ & 20 & 24 & \\
\hline \multicolumn{5}{|l|}{ Sex } \\
\hline Male & $60(63.2)$ & 23 & 37 & 0.671 \\
\hline Female & $35(36.8)$ & 15 & 20 & \\
\hline \multicolumn{5}{|l|}{$\mathrm{T}$ classification } \\
\hline $\mathrm{T} 1, \mathrm{~T} 2$ & $63(66.3)$ & 25 & 38 & 1.00 \\
\hline $\mathrm{T} 3, \mathrm{~T} 4$ & $32(33.7)$ & 13 & 19 & \\
\hline \multicolumn{5}{|l|}{$\mathrm{N}$ classification } \\
\hline N0 & $78(82.1)$ & 30 & 48 & 0.589 \\
\hline $\mathrm{N} 1, \mathrm{~N} 2$ & $17(17.9)$ & 8 & 9 & \\
\hline \multicolumn{5}{|l|}{ Stage } \\
\hline I, II & $59(62.1)$ & 23 & 36 & 0.831 \\
\hline III, IV & $36(37.9)$ & 15 & 21 & \\
\hline \multicolumn{5}{|l|}{ Histological grade } \\
\hline Well & $80(84.2)$ & 29 & 51 & 0.095 \\
\hline Moderate, poor & $15(15.8)$ & 9 & 6 & \\
\hline \multicolumn{5}{|l|}{ Depth of invasion } \\
\hline$<4 \mathrm{~mm}$ & $34(35.8)$ & 11 & 31 & 0.0202 \\
\hline$\geq 4 \mathrm{~mm}$ & $61(64.2)$ & 27 & 26 & \\
\hline \multicolumn{5}{|l|}{ Vascular invasion } \\
\hline Absent & $68(71.6)$ & 23 & 45 & 0.0647 \\
\hline Present & $27(28.4)$ & 15 & 12 & \\
\hline \multicolumn{5}{|c|}{ Perineural invasion } \\
\hline Absent & $80(84.2)$ & 30 & 50 & 0.266 \\
\hline Present & $15(15.8)$ & 8 & 7 & \\
\hline \multicolumn{5}{|c|}{ Lymph Node Metastasis } \\
\hline Absent & $52(54.7)$ & 13 & 39 & 0.0015 \\
\hline Present & $43(45.3)$ & 25 & 18 & \\
\hline \multicolumn{5}{|l|}{ Distant Metastasis } \\
\hline Absent & $79(83.2)$ & 28 & 51 & 0.0539 \\
\hline Present & $16(16.8)$ & 10 & 6 & \\
\hline \multicolumn{5}{|l|}{ Mortality } \\
\hline Absent & $80(84.2)$ & 28 & 52 & 0.0415 \\
\hline Present & $15(15.8)$ & 10 & 5 & \\
\hline
\end{tabular}

Analysis was carried out with Fischer's exact test. Values in bold indicate statistically significant associations $(\mathrm{P}<0.05)$. AMBP, $\alpha-1$-microglobulin/ bikunin precursor; OSCC, oral squamous cell carcinoma.

death by using univariate and multivariate Cox regression analyses (Table II). In univariate Cox regression analysis, $\mathrm{T}$ classification [HR: 18.8; 95\% confidence interval (CI), 4.95-71.43), N classification (HR, 8.47; 95\% CI, 2.99-23.99), clinical stage (HR, 7.35; 95\% CI, 2.64-20.45), histological 

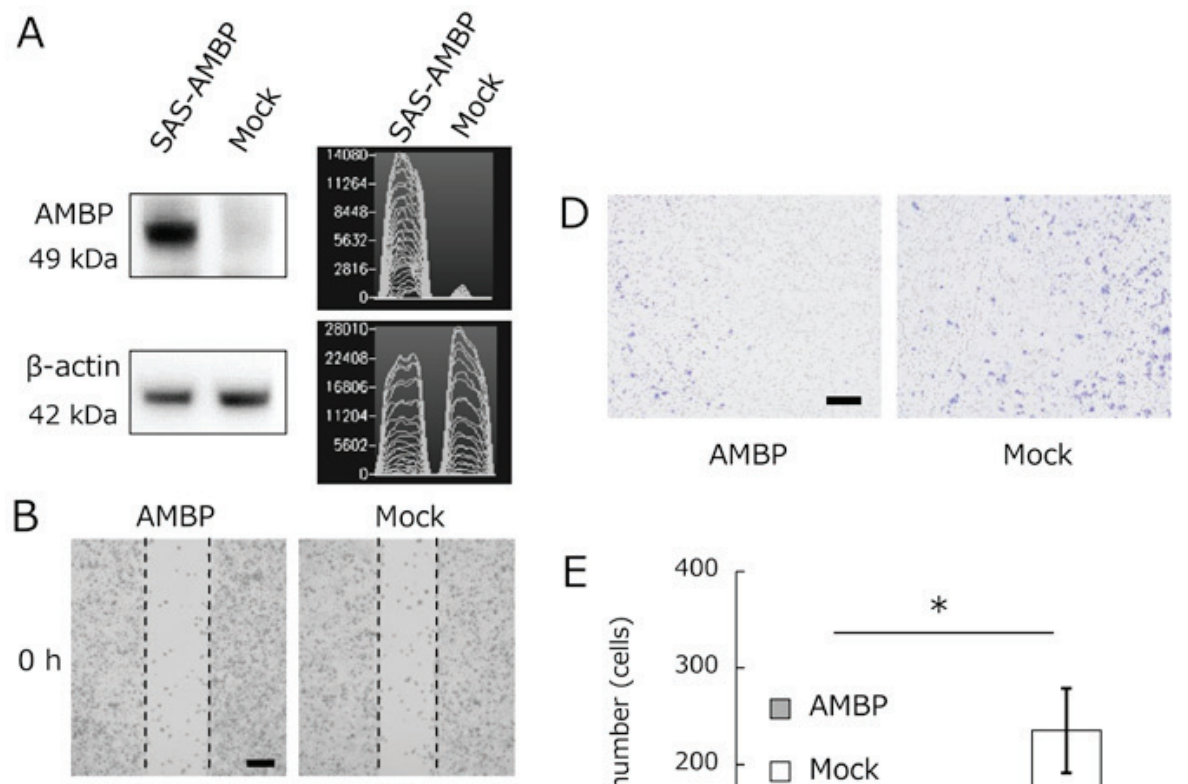

Mock
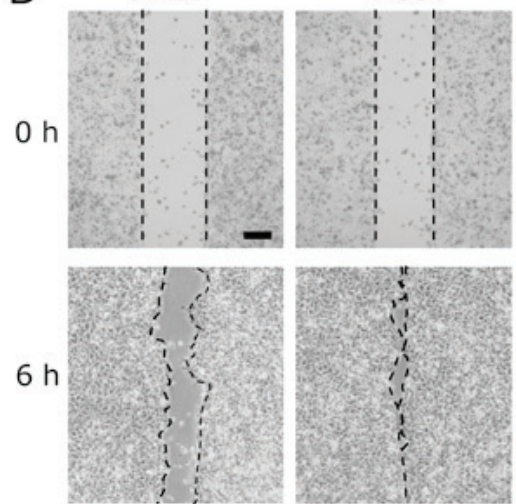

$\mathrm{E}$
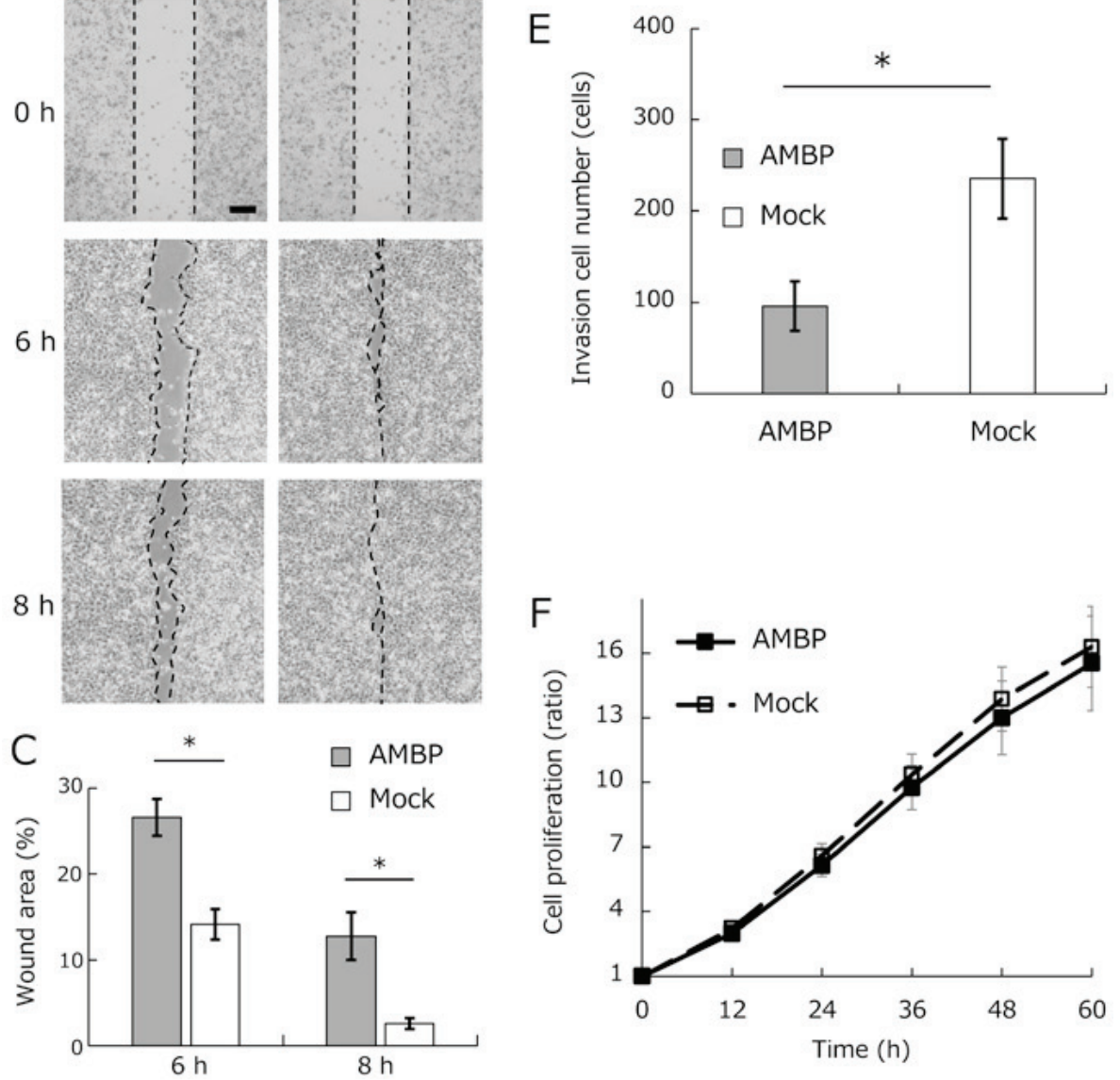

Figure 3. Effect of AMBP overexpression in in vitro assays. (A) Western blot analyses of AMBP expression in SAS cells with transfected AMBP overexpression vector or mock DNA. (B) Representative photographs of wound healing assays using SAS cells transfected with AMBP or mock DNA. Cells are shown at wounding $(0 \mathrm{~h})$ and at 6 and $8 \mathrm{~h}$ later. Bar indicates $200 \mu \mathrm{m}$. (C) Wound healing assay by SAS cells transfected with AMBP overexpression vector or mock DNA. Wound area is shown at 6 and $8 \mathrm{~h}$ later. ${ }^{*} \mathrm{P}<0.05$ (t-test). (D) Representative photographs of Matrigel invasion assays by SAS cells transfected with AMBP overexpression vector or mock DNA. Bar indicates $250 \mu \mathrm{m}$. (E) Matrigel invasion assay by SAS cells transfected with AMBP or mock DNA. ${ }^{*} \mathrm{P}<0.05$ (t-test). (F) Cell proliferation assays by SAS cells transfected with AMBP or mock DNA. The ratio is based on the luminescence as of $0 \mathrm{~h}$. AMBP, $\alpha-1$-microglobulin/bikunin precursor; OSCC, oral squamous cell carcinoma.

grade (HR, 6.73; 95\% CI, 2.72-16.67) and AMBP expression (HR, 0.34; 95\% CI, 0.14-0.86) were significant factors. In multivariate Cox regression analysis, $\mathrm{N}$ classification (HR, 6.55; 95\% CI, 1.76-24.40), histological grade (HR, 9.68; 95\% CI, 3.41-27.64) and AMBP expression (HR, 0.35; 95\% CI, $0.13-0.92$ ) were shown to be significant risk factors for death.

\section{Discussion}

In recent years, molecular-targeted therapies have produced remarkable results in the treatment of various types of cancer $(34,35)$. Cetuximab $(36,37)$, an anti-epidermal growth factor receptor (EGFR) antibody, and Nivolumab (38), a programmed cell death 1 (PD-1) inhibitor, are effective against oral cancer, but there are fewer molecular-targeted agents for oral cancers than for other types of cancer. Therefore, the development of additional molecular-targeted agents is needed, requiring the discovery of molecular markers that can be used for diagnosis and treatment targets.

We identified AMBP as a potential novel biomarker to predict the metastatic potential of OSCC using proteomic analyses. AMBP is a 352-amino acid glycoprotein with a predicted 

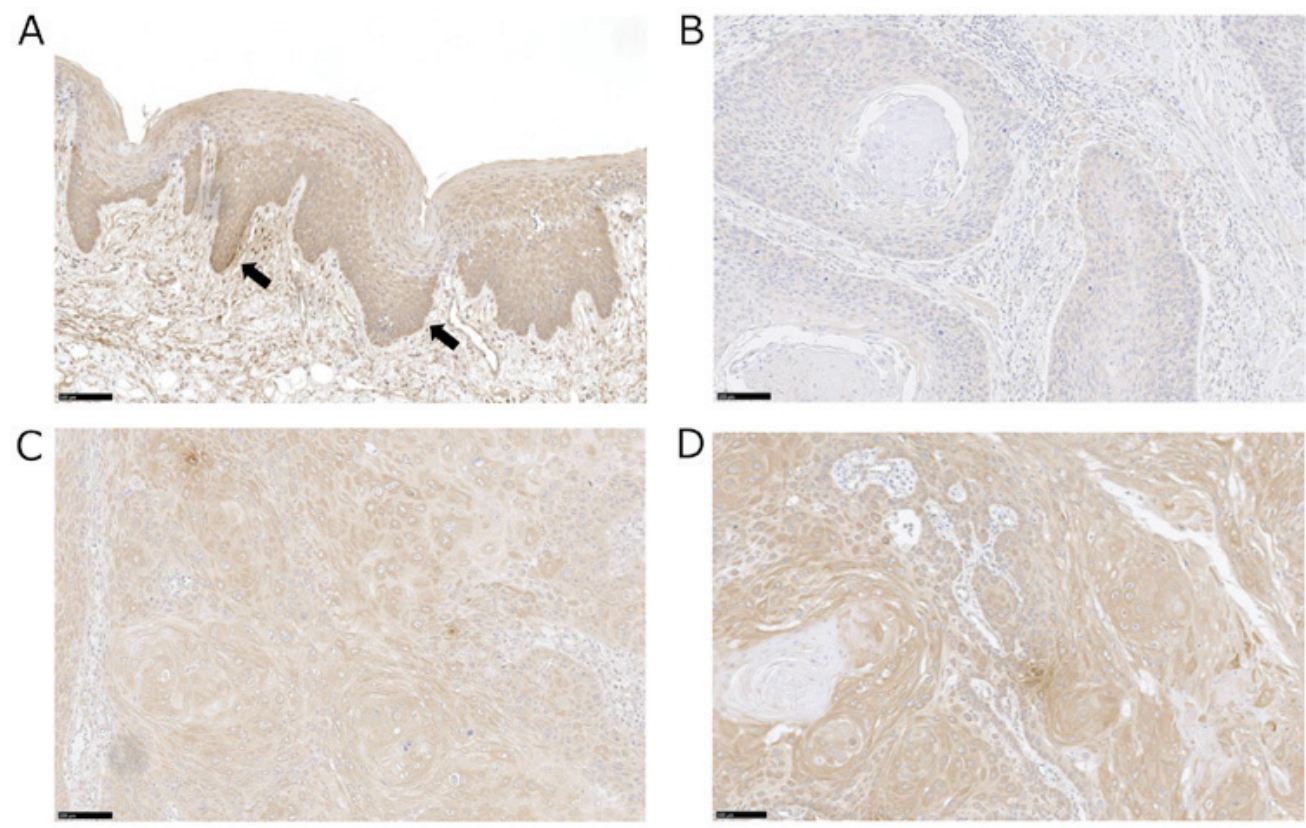

Figure 4. Expression of AMBP in OSCC tissues. Representative expression of AMBP protein in (A) normal oral mucosa and (B-C) OSCC tissues, as determined by immunohistochemistry (IHC). (A) AMBP was strongly expressed in the basal cell layer and stratum spinosum (arrows). (B) Weak expression of AMBP protein in OSCC (intensity score 1); (C) moderate expression in OSCC (intensity score 2); (D) strong expression in OSCC (intensity score, 3). Bar indicates, $100 \mu \mathrm{m}$. AMBP, $\alpha$-1-microglobulin/bikunin precursor; OSCC, oral squamous cell carcinoma.
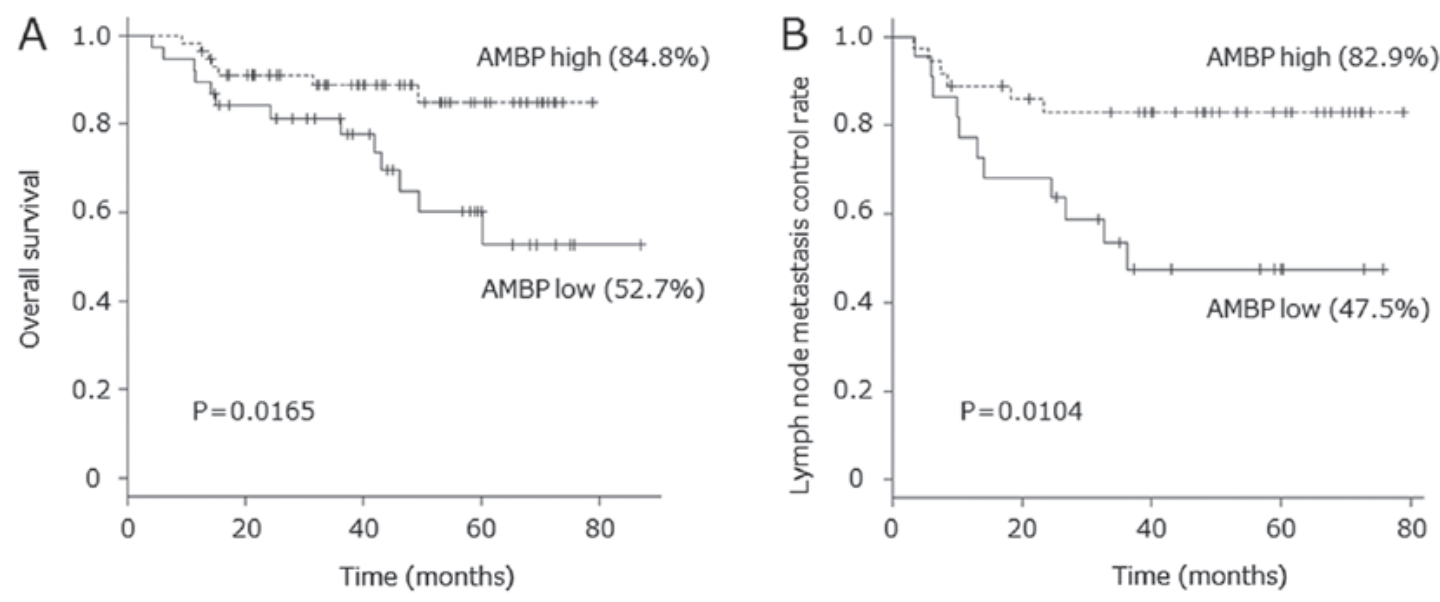

Figure 5. Kaplan-Meier curves of OSCC patients estimated by the expression of AMBP. (A) Overall survival among all patients was significantly lower in the AMBP underexpression group $(\mathrm{P}=0.0165)$. (B) Secondary cervical lymph node metastasis among $58 \mathrm{cN} 0$ patients who did not receive neck dissection was significantly higher in the AMBP underexpression group $(\mathrm{P}=0.0104)$. AMBP, $\alpha-1$-microglobulin/bikunin precursor; OSCC, oral squamous cell carcinoma.

molecular weight of $39 \mathrm{kDa}$, and is normally highly expressed in the liver and can be detected in plasma and urine. Its precursor is proteolytically processed into two distinct functional proteins: $\alpha$-1-microglobulin, which belongs to the lipocalin transport superfamily and plays a role in the regulation of inflammatory processes (39); and bikunin, which is a urinary trypsin inhibitor belonging to the Kunitz-type protease inhibitor superfamily that plays an important role in many physiological and pathological processes, such as modulating cell growth, blocking cellular calcium uptake, and participating in inflammation (40). Recently, associations between AMBP or bikunin and various malignant tumors have been reported $(18,19)$; however, to the best of our knowledge, no report for OSCC is available to date.

The present study suggests that AMBP plays an important role in the invasive and migratory ability of OSCC cells. This may be associated with the significant associatoin of AMBP with DOI. In addition, the underexpression of AMBP was a significant risk factor of cervical lymph node metastasis and death in the present study. Therefore, AMBP expression in primary tumors may be a predictive biomarker of cervical lymph node metastasis or a prognostic biomarker in OSCC. A number of previous studies on the impact of depth of tumor invasion in OSCC have led to a consensus that tumors with a larger depth of invasion are associated with an increased risk of cervical lymph node metastasis and a poor survival (41-44). If the change in the invasive and migratory ability of the cells by AMBP expression leads to a difference in DOI, then AMBP may be a reliable predictor of prognosis.

We were not able to determine the direct effects of AMBP on tumor cells, such as by intracellular signaling, at this 
Table II. Hazard ratios for death of patients with OSCC.

\begin{tabular}{|c|c|c|c|c|c|c|c|}
\hline \multirow[b]{2}{*}{ Variable } & \multirow{2}{*}{$\frac{\text { No. of patients }}{n=95 ; n(\%)}$} & \multicolumn{3}{|c|}{ Univariate analysis } & \multicolumn{3}{|c|}{ Multivariate analysis } \\
\hline & & $\mathrm{HR}$ & $95 \% \mathrm{CI}$ & P-value & HR & $95 \% \mathrm{CI}$ & P-value \\
\hline \multicolumn{8}{|l|}{ Age, years } \\
\hline$<67$ & $51(53.7)$ & 1.41 & $0.58-3.42$ & 0.444 & & & \\
\hline$\geq 67$ & $44(46.3)$ & & & & & & \\
\hline \multicolumn{8}{|l|}{ Sex } \\
\hline Male & $60(63.2)$ & 0.51 & $0.21-1.23$ & 0.134 & & & \\
\hline Female & $35(36.8)$ & & & & & & \\
\hline \multicolumn{8}{|l|}{$\mathrm{T}$ classification } \\
\hline $\mathrm{T} 1, \mathrm{~T} 2$ & $63(66.3)$ & 18.8 & $4.95-71.43$ & $<0.001$ & 3.21 & $0.37-27.64$ & 0.289 \\
\hline $\mathrm{T} 3, \mathrm{~T} 4$ & $32(33.7)$ & & & & & & \\
\hline \multicolumn{8}{|l|}{$\mathrm{N}$ classification } \\
\hline No & $78(82.1)$ & 8.47 & $2.99-23.99$ & $<0.001$ & 6.55 & $1.76-24.40$ & 0.005 \\
\hline $\mathrm{N} 1, \mathrm{~N} 2$ & 17 (17.9) & & & & & & \\
\hline \multicolumn{8}{|l|}{ Stage } \\
\hline $\mathrm{I}, \mathrm{II}$ & $59(62.1)$ & 7.35 & $2.64-20.45$ & $<0.001$ & 1.8 & $0.15-21.36$ & 0.643 \\
\hline III, IV & $36(37.9)$ & & & & & & \\
\hline \multicolumn{8}{|l|}{ Histological grade } \\
\hline Well & $80(84.2)$ & 6.73 & $2.72-16.67$ & $<0.001$ & 9.68 & $3.41-27.64$ & $<0.001$ \\
\hline Moderate, poor & $15(15.8)$ & & & & & & \\
\hline \multicolumn{8}{|l|}{ AMBP expression } \\
\hline Low & $38(40.0)$ & 0.34 & $0.14-0.86$ & 0.022 & 0.35 & $0.13-0.92$ & 0.033 \\
\hline High & $57(60.0)$ & & & & & & \\
\hline
\end{tabular}

Univariate and multivariate analysis were carried out with Cox proportional hazards regression model. Values in bold indicate statistically significant associations $(\mathrm{P}<0.05)$. AMBP, $\alpha-1$-microglobulin/bikunin precursor; OSCC, oral squamous cell carcinoma.

time; however, there are reports indicating that the antitumor effects of bikunin, a degradation product of AMBP, is associated with the urokinase-type plasminogen activator (uPA) and urokinase-type plasminogen activator receptor (UPAR) pathway or the mitogen-activated protein kinase (MAPK) signaling pathway $(20,21)$. The uPA-uPAR pathway regulates ECM proteolysis, cell-ECM interactions, and cell signaling via the plasminogen activation system, an extracellular proteolytic cascade (45). MAPK is a serine/threonine kinase and part of a large kinase network, including extracellular regulated kinase 1/2 (ERK), c-Jun NH2-terminal kinase (JNK) and p38 pathways. MAPK signaling regulates a variety of physiological processes, such as cell growth, differentiation, and apoptotic cell death (46). Therefore, the UPA-uPAR pathway and MAPK signaling pathway may be related to the antitumor effect of AMBP. However, according to our results, tumor cell invasive phenotypes were downregulated while proliferation was not changed. Thus, uPA-uPAR may play a more important role than MAPK. There are many reports about the association between the uPA-uPAR pathway and malignant tumors, and several previous studies have reported that the UPA-uPAR pathway controls the invasion and migration of cells by destroying the basal membrane and extracellular matrix $(45,47)$. The uPA-uPAR pathway may be available as a treatment target with a uPA inhibitor if AMBP affects that pathway (48). The underexpression of AMBP may be useful as a target biomarker for treatment in personalized medicine, not only as a predictive biomarker. However, it is considered that does not explained the behavior of cells only in uPA-uPAR pathway, and intracellular signals such as MAPK pathway may affect it combined.

The AMBP gene has been mapped to the 9q32-33 region in humans (39). The long arm of chromosome 9 is thought to contain some putative tumor suppressor genes that are mutated in squamous cell carcinoma (49). In fact, there is a report that some tumor suppressor genes are associated with basal cell nevus syndrome and Ferguson-Smith syndrome on 9q (50). There is also a report that $35 \%$ of head and neck squamous cell carcinoma patients have allelic loss of $9 q(50)$. Therefore, we suggest that AMBP is one of the tumor suppressor genes in OSCC.

Limitations of the present study include the study being designed retrospectively with samples that were obtained from a single institution, and the sample size being small. Also, our cut-off value for AMBP expression in IHC was derived from previous studies (32) and has not yet been confirmed by other evaluation methods.

Further investigations are warranted to determine whether $\alpha-1$-microglobulin or bikunin play an important antitumor role, and to elucidate the mechanisms of intracellular signal transduction by AMBP. Any differences in AMBP expression 
between primary tumors and lymph node metastatic lesions should also be examined.

\section{Acknowledgements}

Not applicable.

\section{Funding}

This study was supported by a Grant-in-Aid for Scientific Research, grant numbers JP15K11271, JP16H05547, and JP16K15833, from the Japan Society for the Promotion of Science (JSPS). The authors would like to thank Forte Inc. for the language editing of this manuscript.

\section{Availability of data and materials}

All data generated or analyzed during this study are included in this published article or are available from the corresponding author upon reasonable request.

\section{Authors' contributions}

SS, TO and TS were involved in the conception and design of the study. SS and TO performed experiments, analyzed data and drafted the manuscript. NM, NT, TN and KH interpreted the data and assisted in manuscript preparation. All the authors have read and approved the final version of the manuscript.

\section{Ethics approval and consent to participate}

This study was approved by the Research Ethics Committee of Tokyo Dental College (no. 709), and informed consent was obtained from the patients according to a protocol.

\section{Patient consent for publication}

Not applicable.

\section{Competing interests}

The authors declare that they have no competing interests.

\section{References}

1. Ferlay J, Soerjomataram I, Dikshit R, Eser S, Mathers C, Rebelo M, Parkin DM, Forman D and Bray F: Cancer incidence and mortality worldwide: Sources, methods and major patterns in GLOBOCAN 2012. Int J Cancer 136: E359-E386, 2015.

2. Rana M, Kanatas A, Herzberg PY, Khoschdell M, Kokemueller H, Gellrich NC and Rana M: Prospective study of the influence of psychological and medical factors on quality of life and severity of symptoms among patients with oral squamous cell carcinoma. Br J Oral Maxillofac Surg 53: 364-370, 2015.

3. Kademani D: Oral cancer. Mayo Clin Proc 82: 878-887, 2007.

4. Chi AC, Day TA and Neville BW: Oral cavity and oropharyngeal squamous cell carcinoma - an update. CA Cancer J Clin 65 401-421, 2015.

5. Shiboski CH, Schmidt BL and Jordan RCK: Tongue and tonsil carcinoma: Increasing trends in the U.S. population ages 20-44 years. Cancer 103: 1843-1849, 2005.

6. Choi SW, Moon EK, Park JY, Jung KW, Oh CM, Kong HJ and Won YJ: Trends in the incidence of and survival rates for oral cavity cancer in the Korean population. Oral Dis 20: 773-779, 2014.
7. Patel SC, Carpenter WR, Tyree S, Couch ME, Weissler M, Hackman T, Hayes DN, Shores C and Chera BS: Increasing incidence of oral tongue squamous cell carcinoma in young white women, age 18 to 44 years. J Clin Oncol 29: 1488-1494, 2011.

8. Chinn SB and Myers JN: Oral Cavity Carcinoma: Current Management, Controversies, and Future Directions. J Clin Oncol 33: 3269-3276, 2015.

9. Ebrahimi A, Zhang WJ, Gao K and Clark JR: Nodal yield and survival in oral squamous cancer: Defining the standard of care. Cancer 117: 2917-2925, 2011.

10. Gellrich NC, Schimming R, Schramm A, Schmalohr D, Bremerich A and Kugler J: Pain, function, and psychologic outcome before, during, and after intraoral tumor resection. J Oral Maxillofac Surg 60: 772-777, 2002.

11. O-charoenrat P, Pillai G, Patel S, Fisher C, Archer D, Eccles S and Rhys-Evans P: Tumour thickness predicts cervical nodal metastases and survival in early oral tongue cancer. Oral Oncol 39: 386-390, 2003.

12. Angadi PV, Patil PV, Hallikeri K, Mallapur MD, Hallikerimath S and Kale AD: Tumor budding is an independent prognostic factor for prediction of lymph node metastasis in oral squamous cell carcinoma. Int J Surg Pathol 23: 102-110, 2015.

13. Srinivas PR, Verma M, Zhao Y and Srivastava S: Proteomics for cancer biomarker discovery. Clin Chem 48: 1160-1169, 2002.

14. Dabbous MK, Jefferson MM, Haney L and Thomas EL: Biomarkers of metastatic potential in cultured adenocarcinoma clones. Clin Exp Metastasis 28: 101-111, 2011.

15. Poli G, Ceni E, Armignacco R, Ercolino T, Canu L, Baroni G, Nesi G, Galli A, Mannelli M and Luconi M: 2D-DIGE proteomic analysis identifies new potential therapeutic targets for adrenocortical carcinoma. Oncotarget 6: 5695-5706, 2015.

16. Merkley MA, Weinberger PM, Jackson LL, Podolsky RH, Lee JR and Dynan WS: 2D-DIGE proteomic characterization of head and neck squamous cell carcinoma. Otolaryngol Head Neck Surg 141: 626-632, 2009.

17. Bijian K, Mlynarek AM, Balys RL, Jie S, Xu Y, Hier MP, Black MJ, Di Falco MR, LaBoissiere S and Alaoui-Jamali MA: Serum proteomic approach for the identification of serum biomarkers contributed by oral squamous cell carcinoma and host tissue microenvironment. J Proteome Res 8: 2173-2185, 2009.

18. Cohen A, Wang E, Chisholm KA, Kostyleva R, O'ConnorMcCourt M and Pinto DM: A mass spectrometry-based plasma protein panel targeting the tumor microenvironment in patients with breast cancer. J Proteomics 81: 135-147, 2013.

19. 19. Bayraktar E, Igci M, Erturhan S, Igci YZ, Karakok M, Gogebakan B, Ulasli M, Cakmak EA and Arslan A: Reduced gene expression of bikunin as a prognostic marker for renal cell carcinoma. Exp Oncol 36: 107-111, 2014.

20. Kobayashi H, Suzuki M, Kanayama N, Nishida T, Takigawa M and Terao T: Suppression of urokinase receptor expression by bikunin is associated with inhibition of upstream targets of extracellular signal-regulated kinase-dependent cascade. Eur J Biochem 269: 3945-3957, 2002.

21. Suzuki M, Kobayashi H, Tanaka Y, Hirashima Y, Kanayama N, Takei Y, Saga Y, Suzuki M, Itoh H and Terao T: Suppression of invasion and peritoneal carcinomatosis of ovarian cancer cell line by overexpression of bikunin. Int J Cancer 104: 289-302, 2003.

22. Koike H, Uzawa K, Nakashima D, Shimada K, Kato Y, Higo M, Kouzu Y, Endo Y, Kasamatsu A and Tanzawa H: Identification of differentially expressed proteins in oral squamous cell carcinoma using a global proteomic approach. Int J Oncol 27: 59-67, 2005.

23. Onda T, Uzawa K, Nakashima D, Saito K, Iwadate Y, Seki N, Shibahara T and Tanzawa H: Lin-7C/VELI3/MALS-3: An essential component in metastasis of human squamous cell carcinoma. Cancer Res 67: 9643-9648, 2007.

24. Nishikawa H, Ooka S, Sato K, Arima K, Okamoto J, Klevit RE, Fukuda $M$ and Ohta T: Mass spectrometric and mutational analyses reveal Lys-6-linked polyubiquitin chains catalyzed by BRCA1-BARD1 ubiquitin ligase. J Biol Chem 279: 3916-3924, 2004.

25. Dyrlund TF, Poulsen ET, Scavenius C, Sanggaard KW and Enghild JJ: MS Data Miner: A web-based software tool to analyze, compare, and share mass spectrometry protein identifications. Proteomics 12: 2792-2796, 2012.

26. Hao P, Ren Y, Tam JP and Sze SK: Correction of errors in tandem mass spectrum extraction enhances phosphopeptide identification. J Proteome Res 12: 5548-5557, 2013. 
27. Sakuntabhai A, Ruiz-Perez V, Carter S, Jacobsen N, Burge S, Monk S, Smith M, Munro CS, O'Donovan M, Craddock N, et al: Mutations in ATP2A2, encoding a $\mathrm{Ca}^{2+}$ pump, cause Darier disease. Nat Genet 21: 271-277, 1999.

28. Ruiz-Perez VL, Carter SA, Healy E, Todd C, Rees JL, Steijlen PM, Carmichael AJ, Lewis HM, Hohl D, Itin P, et al: ATP2A2 mutations in Darier's disease: Variant cutaneous phenotypes are associated with missense mutations, but neuropsychiatric features are independent of mutation class. Hum Mol Genet 8: 1621-1630, 1999.

29. Ogane S, Onda T, Takano N, Yajima T, Uchiyama T and Shibahara T: Spleen tyrosine kinase as a novel candidate tumor suppressor gene for human oral squamous cell carcinoma. Int J Cancer 124: 2651-2657, 2009.

30. Livak KJ and Schmittgen TD: Analysis of relative gene expression data using real-time quantitative PCR and the 2(-Delta Delta C(T)) method. Methods 25: 402-408, 2001.

31. Lydiatt WM, Patel SG, O'Sullivan B, Brandwein MS, Ridge JA, Migliacci JC, Loomis AM and Shah JP: Head and Neck cancersmajor changes in the American Joint Committee on Cancer eighth edition cancer staging manual. CA Cancer J Clin 67 : 122-137, 2017.

32. Hamm A, Veeck J, Bektas N, Wild PJ, Hartmann A, Heindrichs U, Kristiansen G, Werbowetski-Ogilvie T, Del Maestro R, Knuechel R, et al: Frequent expression loss of Inter-alpha-trypsin inhibitor heavy chain (ITIH) genes in multiple human solid tumors: A systematic expression analysis. BMC Cancer 8: 25-40, 2008.

33. Kanda Y: Investigation of the freely available easy-to-use software 'EZR' for medical statistics. Bone Marrow Transplant 48: 452-458, 2013

34. Slamon DJ, Leyland-Jones B, Shak S, Fuchs H, Paton V, Bajamonde A, Fleming T, Eiermann W, Wolter J, Pegram M, et al: Use of chemotherapy plus a monoclonal antibody against HER2 for metastatic breast cancer that overexpresses HER2. N Engl J Med 344: 783-792, 2001.

35. Topalian SL, Hodi FS, Brahmer JR, Gettinger SN, Smith DC, McDermott DF, Powderly JD, Carvajal RD, Sosman JA, Atkins MB, et al: Safety, activity, and immune correlates of anti-PD-1 antibody in cancer. N Engl J Med 366: 2443-2454, 2012.

36. Bonner JA, Harari PM, Giralt J, Cohen RB, Jones CU, Sur RK, Raben D, Baselga J, Spencer SA, Zhu J, et al: Radiotherapy plus cetuximab for locoregionally advanced head and neck cancer: 5 -year survival data from a phase 3 randomised trial, and relation between cetuximab-induced rash and survival. Lancet Oncol 11: 21-28, 2010.

37. Vermorken JB, Mesia R, Rivera F, Remenar E, Kawecki A, Rottey S, Erfan J, Zabolotnyy D, Kienzer H-R, Cupissol D, et al: Platinum-based chemotherapy plus cetuximab in head and neck cancer. N Engl J Med 359: 1116-1127, 2008.
38. Ferris RL, Blumenschein G Jr, Fayette J, Guigay J, Colevas AD, Licitra L, Harrington K, Kasper S, Vokes EE, Even C, et al: Nivolumab for Recurrent Squamous-Cell Carcinoma of the Head and Neck. N Engl J Med 375: 1856-1867, 2016.

39. Akerström B, Lögdberg L, Berggård T, Osmark $P$ and Lindqvist A: $\alpha(1)$-Microglobulin: A yellow-brown lipocalin. Biochim Biophys Acta 1482: 172-184, 2000.

40. Fries E and Blom AM: Bikunin - not just a plasma proteinase inhibitor. Int J Biochem Cell Biol 32: 125-137, 2000.

41. Tanaka Y, Kobayashi H, Suzuki M, Kanayama N, Suzuki M, Yamakawa T, Morishita $\mathrm{H}$ and Terao T: Reduced bikunin gene expression as a factor of poor prognosis in ovarian carcinoma. Cancer 98: 424-430, 2003.

42. Pentenero M, Gandolfo S and Carrozzo M: Importance of tumor thickness and depth of invasion in nodal involvement and prognosis of oral squamous cell carcinoma: A review of the literature. Head Neck 27: 1080-1091, 2005.

43. D'Cruz AK, Vaish R, Kapre N, Dandekar M, Gupta S, Hawaldar R, Agarwal JP, Pantvaidya G, Chaukar D, Deshmukh A, et al; Head and Neck Disease Management Group: Elective versus therapeutic neck dissection in node-negative oral cancer. N Engl J Med 373: 521-529, 2015.

44. Dirven R, Ebrahimi A, Moeckelmann N, Palme CE, Gupta R and Clark J: Tumor thickness versus depth of invasion - Analysis of the 8th edition American Joint Committee on Cancer Staging for oral cancer. Oral Oncol 74: 30-33, 2017.

45. Smith HW and Marshall CJ: Regulation of cell signalling by uPAR. Nat Rev Mol Cell Biol 11: 23-36, 2010.

46. Junttila MR, Li SP and Westermarck J: Phosphatase-mediated crosstalk between MAPK signaling pathways in the regulation of cell survival. FASEB J 22: 954-965, 2008.

47. Shi Z and Stack MS: Urinary-type plasminogen activator (uPA) and its receptor (UPAR) in squamous cell carcinoma of the oral cavity. Biochem J 407: 153-159, 2007.

48. Montuori N, Pesapane A, Rossi FW, Giudice V, De Paulis A, Selleri $\mathrm{C}$ and Ragno P: Urokinase type plasminogen activator receptor (uPAR) as a new therapeutic target in cancer. Transl Med UniSa 15: 15-21, 2016.

49. Nishiwaki T, Daigo Y, Kawasoe T and Nakamura Y: Isolation and mutational analysis of a novel human cDNA, DEC1 (deleted in esophageal cancer 1), derived from the tumor suppressor locus in 9q32. Genes Chromosomes Cancer 27: 169-176, 2000.

50. Ah-See KW, Cooke TG, Pickford IR, Soutar D and Balmain A: An allelotype of squamous carcinoma of the head and neck using microsatellite markers. Cancer Res 54: 1617-1621, 1994. 